\title{
Airborne Fungi in Prison Indoor Environments of Nsukka and Enugu Metropolis, Nigeria
}

\author{
N. Chukwuma Lilian ${ }^{1^{*}}$, B. Enweani Ifeoma ${ }^{1}$, V. Udeogu Chidozie ${ }^{1}$ \\ Okwelogu Izunna Somadinna ${ }^{2}$, O. Arua Chukwuemeka ${ }^{3}$, C. Ukandu Vivian ${ }^{4}$ \\ and C. Asogwa George
}

${ }^{1}$ Department of Medical Laboratory Science, Faculty of Health Sciences and Technology, Nnamdi Azikiwe University, Nnewi Campus, Nnewi.Anambra State, Nigeria.

${ }^{2}$ Department of Parasitology and Entomology, Nnamdi Azikiwe Universityawka, Anambra State, Nigeria.

${ }^{3}$ Department of Medical Laboratory Science, Enugu State Teaching Hospital Park lane Enugu, Enugu

State, Nigeria.

${ }^{4}$ Department of Medical Laboratory Science, Faculty of Health Sciences and Technology, Nnamdi Azikiwe University Nnewi Campus, Nnewi, Nigeria.

${ }^{5}$ Department of Medical Laboratory Science, Ntasiobi Ndi no n'Afufu, Hospital Enugu, Enugu State,

Nigeria.

\section{Authors' contributions}

This work was carried out in collaboration among all authors. All authors read and approved the final manuscript.

Article Information

DOI: 10.9734/ARRB/2021/v36i730405 Editor(s):

(1) Dr. Paola Angelini, University of Perugia, Italy. Reviewers:

(1) Gustavo Lopez Badilla, Universidad de Estudios Avanzados (UNEA), Mexico

(2) Suhasini Bhatnagar, RUS Industries, India. (3) P. Brindha Devi, Vels University, India. Complete Peer review History: https://www.sdiarticle4.com/review-history/70249

Original Research Article

Received 15 May 2021

Accepted 20 July 2021

Published 02 August 2021

\section{ABSTRACT}

Air borne fungi are transmitted through the air which can cause respiratory infections in human leading to allergies, asthma and diseases of the respiratory tract. The study is to determine the prevalence of fungi isolates in Enugu and Nsukka indoor prison environments and the possible effects on the respiratory tracts of the prison inmates. Institutions that accommodate large number of people such as Prisons, schools and hospitals are prone to airborne diseases due to overcrowded and unhygienic environment. The study was carried out using convenience sampling 
method and health based questionnaires. One hundred and forty (140)samples were analyzed consisting prison offices(48),inmates cells (28), lavatory (16),furniture(8), nasal swabs(20) and hostels(20). AC single impactor with high vacuum pump was used for indoor air sample collection; thermometer was used in measuring the temperature of the room and hygrometer for measuring the humidity. Sterile swab was used in collection of nasal samples, walls, furniture, toilets and bathrooms. Sabouraund dextrose agar $(0.05 \mu \mathrm{g}$ Chloramphenicol and $1 \mu \mathrm{g}$ of Streptomycin), Malt extract agar, Chromagar, Brain heart infusion agar, and Nutrient agar were used for culture media for isolation of fungi respectively. The data generated from this research was analyzed using SPSS statistical software version 23. The result obtained showed that the percentage distribution of fungi isolates in prison offices were $60.9 \%, 57.4 \%$ in Nsukka and Enugu respectively while the percentage distribution percentage distribution of fungi isolates in prison cells were $42.6 \%$ and $39.1 \%$ in Enugu and Nsukka respectively. There was a significant difference in the distribution of fungal isolates at $P=0.042$. The indoor temperature and humidity of Enugu and Nsukka were the same at $\mathrm{P}>0.05$ using ANOVA, when compared with the hostels that served as control. Considering the public health effects of these airborne fungi, appropriate measures should be put in place in prison indoor environment to prevent the growth of moulds and yeast and its dissemination.

Keywords: Airborne fungi; prison indoor environment; prevalence.

\section{INTRODUCTION}

Air borne pathogens are diseases transmitted through the air and most of the airborne microorganisms originate from natural resources such as soil, lakes, animals and humans. Moreover, agricultural practices, health care units and industrial operations such as sewage treatment, animal rendering, fermentation process and food processing plants also emit viable microorganisms into the air [1]. Airborne particles are major causes of respiratory ailments of human causing allergies, asthma and pathogenic infections of the respiratory tract. Air pollution plays a role in air borne diseases which is linked to asthma. Moulds are particularly source of indoor air pollution because of their ability to produce harmful spores and mycotoxins. Both indoor air and outdoor air can become polluted by pesticides. [2]. Most contagious human pathogens have evolved to such dependence on man's habitats for transmission that they lack any ability to survive outdoors for long. In contrast, the non-contagious pathogens, including the fungi, environmental bacterial and some animal pathogens have maintained the ability to survive in the environment [3].

Air is a resource that supplies us with oxygen which is essential for our bodies to live. Pure air is a mixture of gases that are invisible, colourless and odourless, consisting $78 \%$ nitrogen, $21 \%$ oxygen, and other gases as well as varying amounts of water vapour [4]. This pure air can become contaminated in various ways affecting humans, plants and animals. Microorganisms are transmitted by air, but do not grow and reproduce in air, because the air does not contain the necessary amount of moisture and nutrients needed for growth and metabolism [5].This can be caused by exposure to a source; an infected person or animal, mouth, nose cut or needle puncture, therefore it can be spread via respiratory droplets. Sinus congestion, coughing and sore throats are examples of inflammation of the upper respiratory air way due to these air borne agents [6]. Bio aerosols may consist of bacteria, fungi, viruses, microbial toxins, pollens, plant fibres. Fungal spores which are found in air consists of Alternaria, Cladosporium, Penicilium and Aspergillus found in both polar and non polar air masses [3].

Indoor bio aerosols are natural or artificial particles of biological origin suspended in the air and these particles are referred to as organic dust. Moisture built up inside buildings may arise from water penetrating compromised areas of the building envelope or skin, from plumbing leaks, from condensation due to improper ventilation or from ground moisture penetrating part [1].The presence of undesirable bio aerosols is often associated with sick building syndrome. These include furnishings, building materials, fungal contamination with the walls, ceilings and floor cavities by movement of cells, spores and cell fragments through wall openings and gaps at structural joints. Lack of fresh air due to increased insulation of buildings, poorly regulated temperature, relative humidity levels and poorly maintained ventilation system are factors that can leads to poor quality air, [2]. The allergenic properties of mould and the ability to 
trigger episodes in persons that already have asthma, serious respiratory diseases emanates from the indoor air quality. Growth of mould can be inhibited by keeping humidity level below $50^{\circ} \mathrm{C}[7]$.

The quality of indoor air is necessary especially in institutions that accommodates a large number of people such as prison because contaminated air can cause both mild and serious irritating health conditions [4]. Environmental monitoring of air can be done using viable monitoring and non-viable particulate count monitoring. To ensure quantitative health of indoor air, the frequency of effective turnover of interior air replacement with outside air, use of air filters that can trap some of the air pollutants should be adhered .Urgent attention of the government and prison authority on the welfare of the prisoners is highly needed. Decongestion of inmates, bed spacing, adequate health care and proper sanitation would reduce the risk of outbreak of fungi in indoor environment of the prisons [8].

\subsection{Aim}

This study is aimed at determining the air borne fungi isolates in the two prison indoor environment in Enugu and Nsukka metropolis, Nigeria.

\section{MATERIALS AND METHODS}

The study was done in Enugu state. Enugu is the capital of Enugu state in Nigeria. The city has a population of 722,664 and popularly called Coal city, known for its coal mining in the past. Nsukka is a city located in Enugu state and has an estimated population of inhabitants at about 941,000 .Enugu prison is a maximum security prison that has a capacity of about 638 inmates while Nsukka prison is located at Nsukka Local government head quarters corporate office and it is a medium prison that has a carrying capacity of 363 inmates $[9,10]$.

\subsection{Study Subjects and Enrolment}

The prison officers and inmates were recruited in this research. Indoor samples were collected for fungi in prison offices, cells, clinical admission ward and tertiary hostels in Medical Laboratory Science and Technology, Daughters of Divine Love Eha-alumona Nsukka and Enugu respectively, that served as control. Nasal swab samples were collected from patients in clinical admission ward, Samples from walls, toilet seats, furniture and bathroom surface were also collected. The research work was done in
University Teaching Hospital Ituku Ozalla, Enugu state. The study was carried out from September 2017-November 2017.

\subsection{Inclusion Criteria}

Subjects who:

(a) Are obviously sick

(b) Prison inmates who have been previously admitted.

\subsection{Exclusion Criteria}

Subjects who:

(a) Apparently healthy prisoners.

\subsection{Study Design}

An investigative cross sectional study was employed for this research. The study was carried out to determine the quality of air in prison offices, cells, swabs from furniture, toilets, bathroom surfaces, nasal swab samples from patients in the clinical ward with regards to health status of the prisoners in Nsukka and Enugu in Enugu state. Questionnaire was issued and the focus was on prison offices, cells, length of stay in the prison, the number of occupants in the cell that can influence the growth of concentration of airborne fungi and bacteria in indoor environment. In Enugu, 51 cells were available with population of 1833 males while Nsukka had (7) seven apartments with population of 363 males. Nasal swab was collected from patients that had signs and symptoms of respiratory problems in the clinical admission ward of both Nsukka and Enugu inmates. Ten rooms each were sampled in a tertiary hostel of School of Medical Laboratory Science and Technology, Daughters of Divine Love Eha-alumona Nsukka and Enugu respectively, which served as a control. Animal pathogenicity test was done using thirty two (32) adult albino rats. Thirty adult albino rats were used for both fungal and bacterial isolates collected from both the environment and nasal swabs which were treated in three groups, viable, non -viable and immunosuppressed, while two (2) adult albino rats were used as controls.

\subsection{Sample Size}

Minimum sample size $(\mathrm{N})$ was obtained by using the formula [11]

Calculation formula: $N=z^{2} \times p(1-p) / d^{2}$ 
$\mathrm{N}=$ minimum sample size.

$\mathrm{P}=$ prevalence of airborne pathogens (5\%) [12]

$D=$ desired level of significance $=0.05(5 \%)$

$Z$ =confidence interval=1.96(95\%) C.I

$\mathrm{N}=1.96^{2} \times 0.05(1-0.05) / 0.05^{2}=72.9$, appropriately 73 . A total of 140 samples were used for this study.

\subsection{Sampling Technique}

Convenience sampling method was adopted to select 50 sites each from Enugu and Nsukka prisons because of its accessibility and convenience.

\subsection{Sample Collection}

\subsubsection{Sample collection and preparation}

Convenience sampling method was used in collection of indoor air using active monitoring which includes air sampler (AC single stage impactor with high pressure pump ) and sterile swabs stick for collection of samples from furniture (tables, chairs), toilets and bathrooms, clinical admission wards, offices and cells. Samples were collected according to American Conference of Industrial Hygienist (ACGIH) guideline which accepts sampling of bio aerosols in duplicates or possibly triplicate. An agar plate (20mls) of (Malt extract agar, Nutrient agar, Brain heart infusion blood agar, Chromagar (Candida species), Sabouraud dextrose agar supplemented with $(0.05 \mu \mathrm{g} / \mathrm{ml}$ Chloramphenicol and $1 \mu \mathrm{g} / \mathrm{ml}$ Streptomycin) was placed inside the AC single stage one at a time which was connected to a pump operating at $28.3 \mathrm{~L} / \mathrm{min}$. These culture media were used for cultivation of fungi. Agar plates were sampled for five minutes each, after which the agar plates were removed and sent to the laboratory for analysis. The temperature and the humidity of indoor environment were measured using wall thermometer and hygrometer.

Nasal swab samples were aseptically collected by inserting and swabbing a sterile swab into the nostril and then placed back into the swab container. The sample was aseptically cultured in Malt extract agar, Chromagar, Sabouraund Dextrose agar, Brain heart infusion blood agar and Nutrient agar. The samples collected were incubated at $25^{\circ} \mathrm{C}$ for 7 days and was checked daily for fungi growth respectively.

\subsubsection{Laboratory methods and procedures}

The reagents used were commercially purchased and manufacturer's instruction was strictly adhered.

\subsection{Media Preparation}

Malt extract agar, Sabouraund dextrose agar, Brain heart infusion blood agar, Chromagar (for Candida species), Nutrient agar, were prepared for isolation of fungi respectively. Biochemical test was done such as yeast fermentation, germ tube test; identification techniques such as direct microscopy- normal saline, Indian ink, potassium hydroxide solution, lactophenol cotton blue and gram stain were employed for identification of the organisms, as well as manual and control charts

\subsection{Isolation Procedure}

The microorganisms were isolated from nasal swab from sick patients, prison offices and prison cells, furniture, walls, bathroom and toilets surfaces in Enugu and Nsukka prison indoors. Fungi spore for inoculation was prepared by culturing each sample in Sabouraund dextrose agar, Malt extract agar, Chromagar as well as brain heart infusion blood agar and Nutrient agar respectively. Incubation for fungi growth was left for seven days at $25^{\circ} \mathrm{C}$ and was checked daily for growth. The fungi spores were harvested by addition of sterile normal saline, shaking thoroughly in the glass tube. Some of the fungal spores isolated were Aspergillius fumigatus, Candida albicans, Penicillum chrysogenum, and Cryptococcus neoformans.

\subsection{Pathogenicity Test Procedure}

A total of thirty two (32) adult albino rats were used in this study. The rats were purchased and bred in animal house of Nnamdi Azikiwe University,Nnewi Campus. The animals were taken care of, for one week. They were kept under strict hygienic condition during and before introducing the isolates. The cage used for the rats were thoroughly cleaned from time to time. The albino rats were provided with food and clean water and observed daily for any morbidity or mortality. All the animals were adjudged to be healthy. Each albino rats were anaesthesized by placing it in a jar with a wire mesh floor, moistened with chloroform (Abbot laboratories,North Chicago) and observed for decreased mobility and unsteady gait for 20 
secs. When fully anaestesized the albino rats were removed from the jar and gently placed on a flat table one at a time. $0.5 \mathrm{ml}$ of the suspensions of bacteria and fungi spore isolates from the prison indoor air and nasal samples were inoculated intra trachea into the rats. $0.5 \mathrm{mls}$ of the suspension was inoculated in triplicates: killed organisms of each isolates, live organisms and one rat each was injected with hydrocortisone to suppress the immunity after which live organism was introduced through the trachea. Two negative controls were used, one each for the lung tissues and trachea for both bacteria and fungi respectively, no organism was inoculated in the two adult albino rats. The lungs and the trachea were carefully extracted and checked for any sign of lesion, they were cultured in Brain heart infusion blood agar for microbiological testing. Some of the lungs and tissues were also subjected to histopathological testing. Some of the lungs and trachea showed normal pictomicrograph, while some had epithelial hyperplasia and gradual obstruction of macrophages and polymorphs, mild epithelial destruction and inflammatory cell infiltration and fluid exudation within the stroma with alveolar spaces after 7 days of inoculation of the isolates.

A total of ten organisms were introduced into three groups or triplicates for treatment as explained above. The treated albino rats were kept for a week before sacrificing. Bacterial isolates inoculated were Staphylococcus aureus, Klebsiella pneumoniae, Pseudomonas aeruginosa, Escherichia coli, Streptococcus pyogenes, and Streptococcus pneumonia. Some of the fungal spore isolates inoculated were Aspergillius fumigatus, Candida albicans, Penicillum chrysogenum, and Cryptococcus neoformans. Midline cut through the abdomen was done. Some of the lungs and trachea were carefully extracted and checked for signs of lesions, colorations and pus and were swabbed with sterile swab and cultured in brain heart infusion agar and blood agar media for microbiology testing and incubated for twenty four hours. Some of the lungs tissue and trachea were transferred into a universal container containing $10 \%$ buffered formalin for histopathological examination with haematoxylin and eosin (x100).

\subsection{Tissue Processing}

The tissues were dehydrated in different grades of alcohol $80 \%, 90 \%$ and absolute alcohol. The tissues were cleared using in xylene and impregnated in paraffin wax to solidify after which they were cut and trimmed into ribbons using the microtome knife.

The ribbons were floated on the water surface in the water bath with forceps. The slides were smeared with adhesive and inserted into floatation bath where the section was picked and adhered to slides. The tissue section slides were drained for one minute before drying on a hot plate at $56^{\circ} \mathrm{C}$ for $10 \mathrm{mins}$, regulating the melting point of wax and ready for staining. The sections were hydrated in graded alcohol. The slides were stained using Harris haematoxylin and Eosin staining. Principle: Haematoxylin is a dye which stains acidic structures purplish blue while Eosin a dye that stains basic structure pink red. Commercially prepared Harris haematoxylin (Kelong Scientific and Chemicals.co.Ltd,Nigeria) was used.

Staining procedure: The sections were dewaxed in xylene and hydrated through graded alcohol to water, rinsed in water and stained in Harris haematoxylin for five minutes. It was differentiated in $1 \% \mathrm{HCL}$ in $70 \%$ alcohol, rinsed in water. The tissues were blued in scott tap water for two minutes and counter stained in $1 \%$ eosin stain and washed in running water until eosin is removed after which they were dehydrated in $95 \%$ and absolute alcohols. The sections were cleared in xylene and mounted in DPX and examined under the microscope using 100 oil immersion objective.

Results: Nuclei- blue, Cytoplasm-varying grades of pink. Other tissue structures- pink. Red blood cells-red.

\subsection{Data Analysis}

The data gathered from this research was analyzed using SPSS statistical software version 23. Pearson correlation coefficient, Chi-square, Analysis of variance (ANOVA) was employed. Pvalue of less than $0.05(p<0.05)$ was considered as significant.

\section{RESULTS}

Table 1 percentage distribution of airborne fungi isolates in Enugu and Nsukka prison offices.

In Nsukka prison offices, Aspergillus fumigatus had the highest distribution of $32.1 \%$, Alternaria 
alternata and Candida parapsilosis had the lowest of $3.6 \%$ distribution.

In Enugu prison offices, Penicillum chrysogenum had the highest distribution of $18.5 \%$, Candida pseudotropicalis, Geotrichium, Mucor mucedo, Trichosporon beigelli, Cryptococcus neoformans had the lowest distribution of $3.7 \%$ respectively.

Table 2 percentage distribution of airborne fungi isolates in Enugu and Nsukka prison cells.

In Enugu prison cell, Aspergillus fumigatus had the highest distribution of $35 \%$, Cladosporium cladosporoides 5\% and Trichosporon beigelli 5\% had the lowest distribution respectively.

In Nsukka prison cells, Mucor mucedo had the highest distribution of $44.4 \%$, Rhizopus oryzae and Candida krusei had the lowest distribution of $5.6 \%$ respectively.

Table 3 prevalence of airborne fungi in Nsukka and Enugu prison offices and cells.

The prevalence of fungi isolates in Enugu and Nsukka prison offices were $57.4 \%$ and $60.9 \%$ respectively. In prison cells, Nsukka had $39.1 \%$ and Enugu had $42.6 \%$ respectively.

Table 1. Percentage distribution of airborne fungal isolates in prison offices in Enugu and Nsukka

\begin{tabular}{lll}
\hline Fungi & Percentage (\%) Enugu & Nsukka \\
\hline Alternaria alternata & 0 & $1(3.6)$ \\
Aspergillus fumigatus & $3(11.1)$ & $9(32.1)$ \\
Aspergillus niger & $3(11.1)$ & 0 \\
Candida albicans & 0 & $4(14.3)$ \\
C. krusei & $2(7.4)$ & 0 \\
C. parapsilosis & $5(18.5)$ & $1(3.6)$ \\
C. pseudotropicalis & $1(3.7)$ & 0 \\
Cladosporium cladosporiodes & $1(3.7)$ & $2(7.1)$ \\
Cladosporium herbarum & 0 & $3(10.7)$ \\
Cryptococcocus neoformans & $1(3.7)$ & 0 \\
Geotrichium & $1(3.7)$ & 0 \\
Mucor mucedo & $4(14.8)$ & $3(10.7)$ \\
Penicillum chrysogenum & $5(18.5)$ & $5(17.9)$ \\
Trichosporon beigelli & $1(3.7)$ & 0 \\
Total & 27 & 28 \\
\hline \multicolumn{2}{c}{$x^{2}-$ Chi square, df - Degree of freedom, $p<0.05$ is significant }
\end{tabular}

Table 2. Percentage distribution of airborne fungal isolates in in Nsukka and Enugu prison cells

\begin{tabular}{lll}
\hline Fungi & Percentage (\%) Enugu & Nsukka \\
\hline Aspergillus fumigatus & $7(35)$ & $3(16.7)$ \\
Candida albicans & $2(10)$ & $3(16.7)$ \\
Candida krusei & $3(15)$ & $1(5.6)$ \\
Candida tropicalis & $2(10)$ & $2(11.1)$ \\
Cladosporium cladosporiodes & $1(5)$ & - \\
Mucor mucedo & - & $44.4)$ \\
Rhizopus oryzae & $4(20)$ & $1(5.6)$ \\
Trichosporon beigelli & $1(5)$ & - \\
Total & 20 & 18 \\
\hline \multicolumn{2}{c}{$X^{2}=14.535, d f=7, p=0.042$} \\
\end{tabular}


Table 3. Prevalence of airborne fungal isolates in prison offices and cells in Enugu and Nsukka

\begin{tabular}{lll}
\hline & Fungi & Fungi \\
\hline Prisons & (offices) & (cells) \\
Nsukka & $20(42.6 \%)$ & $18(39.1 \%)$ \\
& 47 & 46 \\
\hline
\end{tabular}

$x^{2}-$ Chi square, $d f-$ Degree of freedom, ${ }^{*} p<0.05$ is significant

$$
x^{2}=0,11, d f=1, P=0.74
$$

\section{DISCUSSION}

Nsukka prison offices had a higher percentage of fungal isolates than Enugu prison offices.

There was a significant difference in the distribution of fungal isolates at $P=0.042$. Different airborne fungi were isolated indoors, some of these organisms were known to be allergenic, pathogenic and toxigenic (Pavan and Manjunth,2014) such as Alternaria alternata, Aspergillus fumigatus, Aspergillus niger, Penicillum chrysogenum, Candida albicans, Candida krusei, Candida parapsilosis, Candida tropicalis, Candida pseudotropicalis Geotrichum, Mucor mucedo, Rhizopus oryzae, Cladosporium cladosporoides, Cladosporium herbarum, Trichosporon beigelli, Cryptococcus neoformans. This is also in line with the findings of Osugwugwu and Onwuka in 2014 that isolated Penicillum, Aspergillus and Bacillus species which were the most commonly isolated microorganism in indoor environment and spores of these fungi are known to be allergic [10].

In this study, airborne yeast were identified from culture plates exposed in prison cells, offices and hostel rooms, Candida species were prevalent and had $35 \%$ in prison cells, $64.5 \%$ in prison offices and $43.3 \%$ in hostel rooms. Aspergillus fumigatus had distribution of $32.5 \%$ in prison offices and $35 \%$ in prison cells and are known to cause aspergillosis and hypersensitivity pneumonitis in immune compromise individuals. In the study of Naziha [13], different airborne yeasts were identified in microhabitat of police prison rooms and opera house. Candida had the dominating genus representing $74.4 \%$ of the total count [10].

The mean prison indoor temperature and humidity of Enugu and Nsukka offices had moderate temperature and high humidity which favoured the growth of these fungi. The presence of fungi in the bathrooms and toilets, walls, furniture may be as a result of damp environment and poor sanitation that favours the growth of these microorganisms. The allergenic properties of mould and the ability to trigger episodes in persons that already have asthma, serious respiratory diseases emanates from the indoor air quality [7].

Nasal samples isolated from the sick patients showed a gram positive organism known as Candida albicans in Enugu and Nsukka prisons. Candida albicans are known to cause inflammation, allergy and infection in the upper respiratory tract. This may also be the cause of respiratory distress, allergy, and persistent cough, signs of sore throat, nose congestion and catarrh which were observed in the clinical admission wards. Overcrowding and inadequate ventilation and poor sanitation in the two prisons may have contributed to poor quality of indoor air. According to Rajesh et al., 2008, the higher levels of microbial contamination are observed when there are many occupants, much bodily movement or dust raising activities. The animal pathogenicity test done with the fungi spores showed both normal and abnormal effects on some of the lungs and trachea of the albino rats, which implies that the organisms can equally have effect on human.

\section{CONCLUSION}

Nsukka prison offices had a higher percentage of fungi isolates than in Enugu prison offices.

The presence of fungi in the indoor environment may be due to poor sanitation, high humidity and moderate temperature, personal hygiene and congestion of the inmates which may have also contributed immensely to the poor quality of indoor air.

Biomedical actions should be taken to reduce the concentration of biological contamination present in prison indoor environment by decongesting prisoners, proper sanitation, adequate ventilation and personal hygiene. 


\section{DISCLAIMER}

The products used for this research are commonly and predominantly use products in our area of research and country. There is absolutely no conflict of interest between the authors and producers of the products because we do not intend to use these products as an avenue for any litigation but for the advancement of knowledge. Also, the research was not funded by the producing company rather it was funded by personal efforts of the authors.

\section{CONSENT}

Oral and Written consent was sought and obtained from all the participants and controller of prisons.

\section{ETHICAL APPROVAL}

Ethical approval was sought for and obtained from Ethical Committee of University Teaching Hospital Ituku Ozalla in Enugu state, Nigeria.

\section{COMPETING INTERESTS}

Authors have declared that no competing interests exist.

\section{REFERENCES}

1. Dawood Jahlil, Mohammed H, Abdolmajid Fadel, Mahmood Alimohammadi. Assessment of airborne bacteria and fungal communities in Shahrekord hospitals; 2021.

DOI.org/10.1155.

2. Arora Dr, Arora B. Medical mycology, Textbook of microbiology CBS publisher, New Delhi. 2012;653-657.

3. Haleem A, Mohan. Fungal pollution of indoor environments and its management. Saudi Journal of Biological Sciences. 2012 ;19(4):405-426.

4. Mandin C, Trantalhdi A, Cattaneo. Assesment of indoor air quality in office buildings across Europe. Journal of Science of the Total Environment. 2017 ;579:169-178.

5. Aaron K, Golblatt M. Aerobiology and its role in the transmission of infectious diseases. Journal of Pathogens. 2013 ;10:1155.
6. Laura E, David S, Gloster J. Predicting infection risk of airborne foot and mouth disease. Journal of the Royal Society Interface. 2008;6(34):455462.

7. Ayanbimpe G, Wapwert S, Danjuma M, Okolo O. Relationship between fungal contamination of indoor air and health problems of some resident in Jos; 2012.

8. Chukwuma LN, Enweani IB, Obeagu E, Udeogu CV, Dilibe EA, Arua COA, Aguchibe UC. Prevalence of airborne bacteria in prison indoor environments located in Nsukka and Enugu Metropolis, Nigeria. World Journal of Pharmateuticals and Life Sciences. 2021;7(5): 142-147.

9. Willie, Lizzie. Nigeria: The Bradt Travel 162-139-7Guide.196.ISBN 1-84162-139-7. 2008.

10. James DO. Spatial distribution of Tuberculosis in Nigeria and its socioeconomic correlates. Lancaster University (United Kingdom); 2017.

11. Naing L, Winn T, Rusli BN. Practical issues in calculating the samples size for prevalence studies. Architecture Orofacial Science. 2005;1:9-14.

12. Ren $P$, Jankum $T$, Leaderer $B P$. Comparisons of seasonal fungal prevalence in indoor and outdoor air and in house dusts of dwellings in one North American country. Journal of Exposure analysis Environmental Epidemiology. 1999;9:560-568.

13. Naziha M, Hassanen. Air borne yeast isolates as biocontaminants at two different indoor environments in Cairo. International Journal of Agric and Biology.1560-8530/6-1013-1022. 2006.

14. Agarawal R. Severe asthma with fungal sensitization. Current Allergy Asthma Report. 2011;5:403-413.

15. Murray PR, Baron EJ, Pfaller MA, Tenover FC. Manual of clinical microbiology $6^{\text {th }}$ edition Washington D.C; 2. 1995.

16. Osuogwugwu FM, Onwuka SC. Indoor quality air sampling for detection of pathogenic bacteria in hospital ward in Lagos, Nigeria. Nigeria Medical Microbiology. 2014;26:2555-256. 
17. Rajesh B, Rattan L.ichhpujani. Microbiology of water and air, essentials of medical microbiology $4^{\text {th }}$ ed. Jaypee brothers publisher. 2008;446-447.
18. Tambeker DH, Gulhane PB, Bharkare D. Studies on environmental monitoring of microbial air flora in hospitals. Journal of Medical Science. 2007;7(1):67-72.

(c) 2021 Lilian et al.; This is an Open Access article distributed under the terms of the Creative Commons Attribution License (http://creativecommons.org/licenses/by/4.0), which permits unrestricted use, distribution, and reproduction in any medium, provided the original work is properly cited.

Peer-review history:

The peer review history for this paper can be accessed here: https://www.sdiarticle4.com/review-history/70249 